UNIVERSITÃT

$D_{E} U_{S} I_{S} S_{E}{ }_{N} U R$ G
Chair for Management Science and Energy Economics

II Prof. Dr. Christoph Weber

Chair for Management Science and Energy Economics

University of Duisburg-Essen

EWL Working Paper

\title{
AN EMPIRICAL ANALYSIS OF LIQUIDITY AND ITS DETERMINANTS IN \\ THE GERMAN INTRADAY MARKET FOR ELECTRICITY
}

\author{
by \\ Dipl. -Kfm. Simon Hagemann* \\ and \\ Prof. Dr. Christoph Weber \\ Submission Date: 08.10.2013 \\ Journal: Energy Economics
}

* Corresponding author. Email: Simon.Hagemann@vattenfall.de 


\begin{abstract}
This paper presents a theoretical and empirical analysis of liquidity in the German intraday market for electricity. Two models that aim at explaining intraday liquidity are developed. The first model considers the fundamental merit-order and intraday adjustment needs as the drivers of liquidity in a perfectly competitive market. The second model relaxes the assumption of perfect competition in the intraday market and assumes that the trading behavior of profit maximizing market participants influences the liquidity provision. The relevance of commonly used liquidity indicators like the bid askspread, resiliency, market depth, price variance, delay and search costs as well as trading volume and the number of trades are analyzed with respect to both models of liquidity. The empirical findings indicate that liquidity in the German intraday market can be explained by the trading model while the purely fundamental model is rejected.
\end{abstract}

\title{
Highlights
}

We develop a fundamental and a trading model of liquidity in the GIME.

Tightness, volatility and trading activity are distinct dimensions of liquidity.

Not only power plant capacities but also trading behavior determine liquidity.

The fundamental model is rejected while the trading model is confirmed.

\section{Keywords}

Intraday market, electricity, liquidity, fundamental model, trading model

JEL-Classification : L94, Q41

\section{SIMON HAGEMANN}

Intraday Manager Power,

Vattenfall Energy Trading GmbH

Dammtorstr. 29-32, 20354 Hamburg

++49-(0)176 / 61930467

Simon.Hagemann@vattenfall.de

\section{CHRISTOPH WEBER}

Chair for Management Science and Energy Economics, University of Duisburg-Essen (Campus Essen) Universitätsstr. 11, 45117 Essen ++49-(0)201 / 183-2966

www.ewl.wiwi.uni-due.de

Christoph.Weber@uni-due.de 


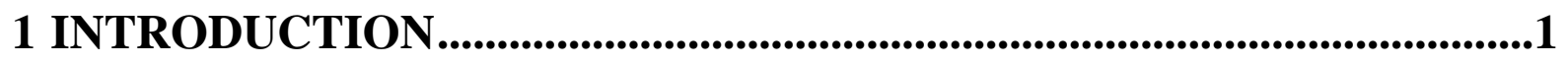

2 THE GERMAN SHORT TERM MARKETS FOR ELECTRICITY ........2

3 THE CONCEPT OF LIQUIDITY AND ITS DETERMINANTS IN

THE GERMAN INTRADAY MARKET FOR ELECTRICITY ................4

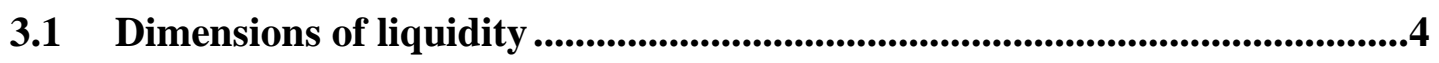

3.2 A fundamental and a trading model of liquidity ......................................6

3.3 Further factors affecting intraday liquidity and trading .........................14

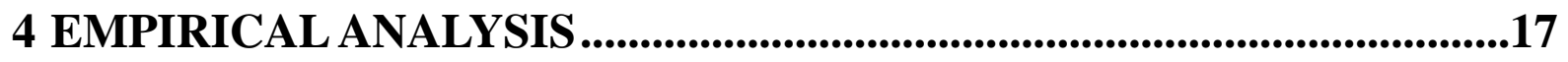

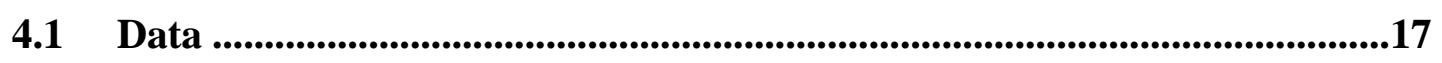

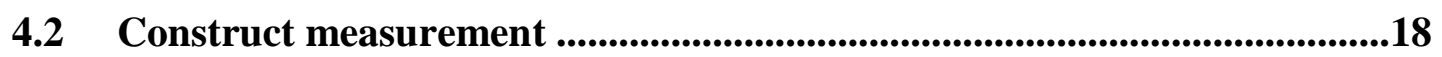

4.3 Empirical results ...............................................................................................................19

4.4 Discussion...............................................................................................23

5 CONCLUSION AND OUTLOOK …....................................................27

Appendices ..........................................................................................................................................29

References ..........................................................................................................30 


\section{INTRODUCTION}

The importance of intraday markets for electricity is increasing constantly in Germany as the need for short term adjustments of conventional energy production due to intermittent generation of renewable energy sources (RES) is raising as Bueno-Lorenzo et al. (2013) stress. In 2012, the installed capacity of intermittent RES amounted to $29 \mathrm{GW}$ wind power and to 25 GW solar power which was more than $30 \%$ of the total installed production capacity. The intermittency of wind and solar power leads to so called forecast errors at the marketing process of RES. The forecast errors correspond to the deviation between the day-ahead planned and marketed and the actually realized electricity production. The forecast error of RES may be traded together with other imbalances like unplanned power plant outages and the load forecast error in the intraday market. Scharff and Amelin (2011) notice that the intraday market enhances system security by relieving the balancing mechanism. ${ }^{1}$ Furthermore all market participants have a monetary interest to correct imbalances on intraday markets because this costs less than purchasing power on the balancing market.

The research target of this paper is to explain liquidity in the German intraday market for electricity (GIME) from 2010 to 2011. According to Sarr and Lybek (2002) liquidity in any market is generally perceived as desirable because it increases allocation and information efficiency. Two models of liquidity are developed. The first model explains the liquidity provision from a fundamental perspective, where only power plant owners with available and flexible power plant capacities offer liquidity while risk-averse impatient traders with intraday imbalances trade against the power plant owners and consume the offered liquidity. In the second model, impatient traders are assumed to be risk neutral and try to increase their revenues with trading strategies including the provision of liquidity to the market in form of limit orders.

Despite its importance for optimization purposes and system security, research about liquidity in the GIME and similar continental European intraday markets is scarce. Weber (2010) stresses the importance of the functioning of the day-ahead and intraday markets to integrate wind energy. For the year 2007, he identifies a low intraday liquidity in terms of trading volume and recommends the adaption of the Spanish intraday market design in order to increase liquidity in the GIME. Borggrefe and Neuhoff (2011) analyze the intraday market as a viable

\footnotetext{
${ }^{1}$ In 2011 the intraday market showed 276 hours with buy trading volumes and 259 hours with sell trading volumes above $3000 \mathrm{MW}$. The average contracted positive balancing capacity which was being held in reserve by the TSOs in 2011 amounted to 4976 MW positive and 5152 MW negative reserve power (Sources: Reserve power data from www.regelleistung.net and intraday trade data provided by the EPEX Spot)
} 
option to decrease balancing costs which are part of the overall wind integration costs in Germany. Furio et al. (2009) focus on the Spanish intraday market liquidity and assess the liquidity risk which could discourage agents to participate in the intraday market. Because in contrast to the GIME, the Spanish intraday market is auction based, their research methods and results are not directly applicable to the GIME.

This paper intends to contribute to the present literature in several ways. First of all the development and empirical falsification of the fundamental and the trading model of liquidity may be the first theoretical approach to the analysis of liquidity in the GIME. Secondly the empirical analysis of commonly used indicators of liquidity like the bid ask-spread, resiliency, market depth, price volatility and trading volume in the GIME has not been undertaken so far. Moreover the theoretical soundness of the commonly used liquidity indicators is scrutinized for the case of intraday markets for electricity.

The paper is organized as follows. In the second chapter, the German short term electricity market design is reviewed. In chapter three, the commonly used dimensions of liquidity are identified based on the existing literature. Afterwards, the fundamental and the trading model of intraday liquidity are developed. Theoretical research hypotheses about the relations between the indicators of liquidity, intraday deviations from the day-ahead planning and the merit order are then worked out. Chapter three ends with an overview of the intraday deviations from the day-ahead planning that the market participants may trade in the GIME and that are used as explanatory variables in the empirical analysis. Chapter four gives an overview of the data used in the empirical analysis. Afterwards, the measurement of the indicators of liquidity is discussed. In chapter 4.3 , the empirical findings on the indicators of liquidity and the results of five regression models with the indicators of liquidity as the dependent variables are presented. Chapter four ends with a discussion of the empirical results and the hypothesis testing. Finally, chapter five summarizes the conclusions, points out the limits of this paper and gives an outlook on further research opportunities.

\section{THE GERMAN SHORT TERM MARKETS FOR ELECTRICITY}

The day-ahead, intraday and balancing markets form the short term markets for electricity in Germany. $^{2}$ In the day-ahead market, energy with physical delivery on the next day " $\mathrm{d}$ " is traded anonymously on a trading platform of the European Power Exchange (EPEX Spot) or

\footnotetext{
${ }^{2}$ Note that the term of balancing market is somewhat misleading in the German context. There are no explicit demand bids, rather the supply of balancing services is selected by the TSOs based on preselected reserve provision bids. Therefore we use rather the term of "balancing services" instead of "balancing market" in the following.
} 
over the counter (OTC). The ETSO (2007) defines OTC trades as bilateral transactions between two known market participants with the possibility to trade non-standard products. In the day-ahead auction, market participants declare their willingness to sell (offer) or to buy (bid) energy at a certain price for each of the 24 hours of the next day. The day-ahead gate closure is at $12 \mathrm{pm}$ each day. The exchange then sorts all available offers by increasing prices which should reflect the power plants' marginal costs. This way, the hourly supply or meritorder curve is created. In a similar procedure the demand curve is created by sorting all bids. In the next step, the hourly day-ahead prices and market clearing volumes are determined by matching forecasted demand and aggregated supply in each delivery hour (Sensfuß et al., 2008). ${ }^{3}$

After the gate closure of the day-ahead market until the moment of physical delivery, trading continues on the intraday market. Unforeseen events after the day-ahead gate closure cause new open positions ${ }^{4}$ in the scheduling of market participants. The intraday market enables and encourages market participants to self-balance upcoming deviations from their previously set day-ahead schedules. Again, trading continues on an exchange or OTC. The EPEX Spot offers an electronic trading platform where intraday trading in and between Germany, France and Austria is conducted. In this transparent and order driven market, liquidity is being provided by public limit orders and in tight market situations by designated market makers. With a limit order, a market participant may trade a certain amount of electricity at a specified price or better. With a market order, a certain amount of electricity is traded immediately at the best price that is currently available (Jiang et al., 2011). Intraday trading for the next day starts at three pm and single hour or block contracts can be traded until 45 minutes before physical delivery. Since December 2011 it is also possible to trade quarters of an hour. The exchange price is a publicly available price and functions as the reference price for OTC trades in the GIME. Zachmann (2008) notes that the prices of OTC trades cannot deviate systematically from the exchange prices because traders usually have the option to trade either on the exchange or OTC and will not accept an offer in one market if trading in the other yields a higher profit.

Shortly before delivery, the TSOs take over the responsibility for all remaining imbalances. To ensure the constant equilibrium between physical demand and supply of the non-storable good electricity at a grid frequency of 50 Hertz in real time, the TSOs make use of pre-

\footnotetext{
${ }^{3}$ Note that some special rules apply for the consideration of so-called block bids encompassing several hours and for the market-coupling with neighboring markets.

${ }^{4}$ An open position of a market participant is a situation where the net of selling and buying commitments towards other market parties is not equal to the net of generation of his suppliers and demand of his customers (ETSO (2007)).
} 
contracted balancing services. According to their required activation time and duration of operation, balancing services can be distinguished into primary, secondary and tertiary reserves. ${ }^{5}$ A balance responsible party's balance group whose net production or consumption deviates from the previously scheduled values will be balanced in real time by the TSO. This way, market participants can close their open positions through the balancing services but will always try to avoid this option for two reasons. Firstly, the market is designed in way that the use of balancing services is always more expensive than self-balancing on the intraday market (BNA, 2012). Secondly, the TSOs may penalize the occurrence of too many imbalances of one market participant with the abrogation of his balancing contract.

On the weekday after physical delivery $(d+1)$, imbalances within one control zone can be traded ex-post until 4:00 pm on the day-after or yesterday market. Here, market participants announce their imbalances from yesterday on the trading platform IntradayS and try to find another market participant with a symmetrical imbalance profile in the same grid area. According to the first come first serve principle, the mutual imbalances get traded at the dayahead price of the day where the imbalance occurred. Settling imbalances on the day-after market is an ex post financial settlement: physically, a short and a long position of the same size within one grid zone already matched to zero during delivery.

\section{THE CONCEPT OF LIQUIDITY AND ITS DETERMINANTS IN THE GERMAN INTRADAY MARKET FOR ELECTRICITY}

\subsection{Dimensions of liquidity}

From a trader's perspective, liquidity can be defined as the ability to exercise a buy or sell order of any size at any time without the price being influenced by this order (Amihud/ Mendelson, 1991; Liu, 2006; Weber, 2010). Amihud (2002) and Arnott and Wagner (1990) emphasize that liquidity is not directly observable because its measurement would require data about the difference between the actual execution price of a trade and the market price that would have prevailed in the absence of the transaction. The theoretical literature agrees that liquidity is a multidimensional construct which is not directly observable (e. g. Amihud, 2002; Kyle, 1985; Liu, 2006; Kempf et al., 2009). Although there is agreement on the multidimensionality of liquidity, disagreement prevails about the dimensions of liquidity, both on the number of dimensions and the actually relevant dimensions. Kyle (1985) identifies three dimensions

\footnotetext{
${ }^{5}$ For a more detailed presentation of the German market for balancing power see Flinkerbusch/ Heuterkes (2010), p. 4713 or Möller et al. (2011), pp. 3-4.
} 
namely tightness, depth and resiliency. Kempf et al. (2009) agree that liquidity has three dimensions but define them as spread, depth and resiliency. Liu (2006) mentions four dimensions of liquidity that are trading volume, trading costs, trading speed and price impact. Amihud and Mendelson (1991) differentiate between three types of illiquidity costs that are the bid-ask-spread (BAS), market impact costs and delay and search costs. Finally Handa and Schwartz (1996) find empirical evidence that short-run price volatility may be influenced by the liquidity provision in the limit order book.

The first dimension which is described in all four sources is called tightness (Kyle, 1985), spread (Kempf et al., 2009), trading costs (Liu, 2005) or BAS (Amihud and Mendelson, 1986). The quoted BAS is defined as the price difference between the best bid and offer price in the limit order-book. With any traded unit, a market participant bears transaction costs due to the BAS which are as high as the absolute value of the execution price minus the average of the best bid and ask price.

The second dimension of liquidity is resiliency. Kyle (1985) defines market resiliency as the rate at which prices in the limit order book bounce back to the competitive level after an uninformative liquidity shock from a sequence of market orders. Foucault et al. (2005) conclude that a high share of impatient traders in stock markets decreases resiliency because these traders place market orders in order to decrease their waiting time until order execution. Patient traders place new limit orders within the prevailing quotes and make the market resilient.

The third dimension is called price impact (Liu, 2006), market-impact costs (Amihud and Mendelson, 1991) or market depth (Kyle, 1985). Amihud and Mendelson (1991) define the price impact from the cost perspective of illiquidity. Illiquidity costs may arise because of an upwards price movement if a good (here electricity) is bought beyond the best ask price or downwards price movement if electricity is sold below the best bid price. The market depth dimension of liquidity is defined as the size of an order flow innovation leading to a change in prices at a given amount (Kyle, 1985). Both definitions can be understood as the movement along a price-demand function which slope is determined by the volumes and prices of electricity in the limit order book. Amihud (2002) and Weber (2010) notice that the lower the volumes and the larger the price differences between the limit orders, the higher will be the slope of the price-demand function and the price impact of a standardized trade. The price impact of a trade causes transaction costs to rise as the market participant has to pay more when buying or earns less when selling.

In stock markets, short-run price volatility is being considered as another dimension of liquidity. The magnitude of price movements due to information driven trading may be influenced 
by the amount of liquidity in the limit order book (Handa and Schwartz, 1996). Furthermore, authors like Ahn et al. (2001), Engle et al. (2011), or Handa and Schwartz (1996) conclude that in stock markets, short-run volatility may encourage the placement of new limit orders which in turn decrease short-run volatility.

The fifth dimension of liquidity are the delay and search costs which are incurred when a trader delays a trade in order to achieve better prices than those currently quoted or reduce market impact costs (Amihud and Mendelson, 1991). Delay and search costs are negatively correlated with the trading speed dimension of liquidity which Liu (2006), p. 632, defines as "the continuity of trading and the potential delay or difficulty in executing an order". Delay and search costs are also negatively correlated with liquidity. If the market shows a perfect liquidity, traders in the GIME are able to close open intraday positions immediately at zero illiquidity costs and delay and search costs are zero as well.

The sixth dimension of liquidity will be named trading activity which consists of trading volume and the number of trades per delivery hour. Because part of the definition of liquidity is the ability to exercise a buy or sell order, Frestad (2012) concludes that trading itself might be an important indicator of liquidity. Trading volume can be defined as the absolute amount of Megawatt hours (MWh) electricity bought or sold per trading hour. Apart from trading volume, the number of trades per hour is an interesting indicator for trading activity as it is probably positively correlated with trading volume and the number of market participants that are active in the market.

\subsection{A fundamental and a trading model of liquidity}

In stock markets, liquidity is capped by the quantity of free floating shares. Yet this cap is rather theoretical at least for major titles included in popular indices which typically have a high number of free floating shares. In contrast, the total amount of liquidity available in the GIME might be explained from a fundamental supply curve model (the so called merit-order) and intraday deviations from the day-ahead planning which may be traded in the intraday market. ${ }^{6}$

\footnotetext{
${ }^{6}$ This paper focuses on the German intraday market. In this and similar European intraday markets (e. g. French, Dutch, Austrian) liquidity might be explained by a fundamental model. Liquidity in the pool based US-market or the Scandinavian intraday markets with a large share of hydro-generation may be explained differently.
} 

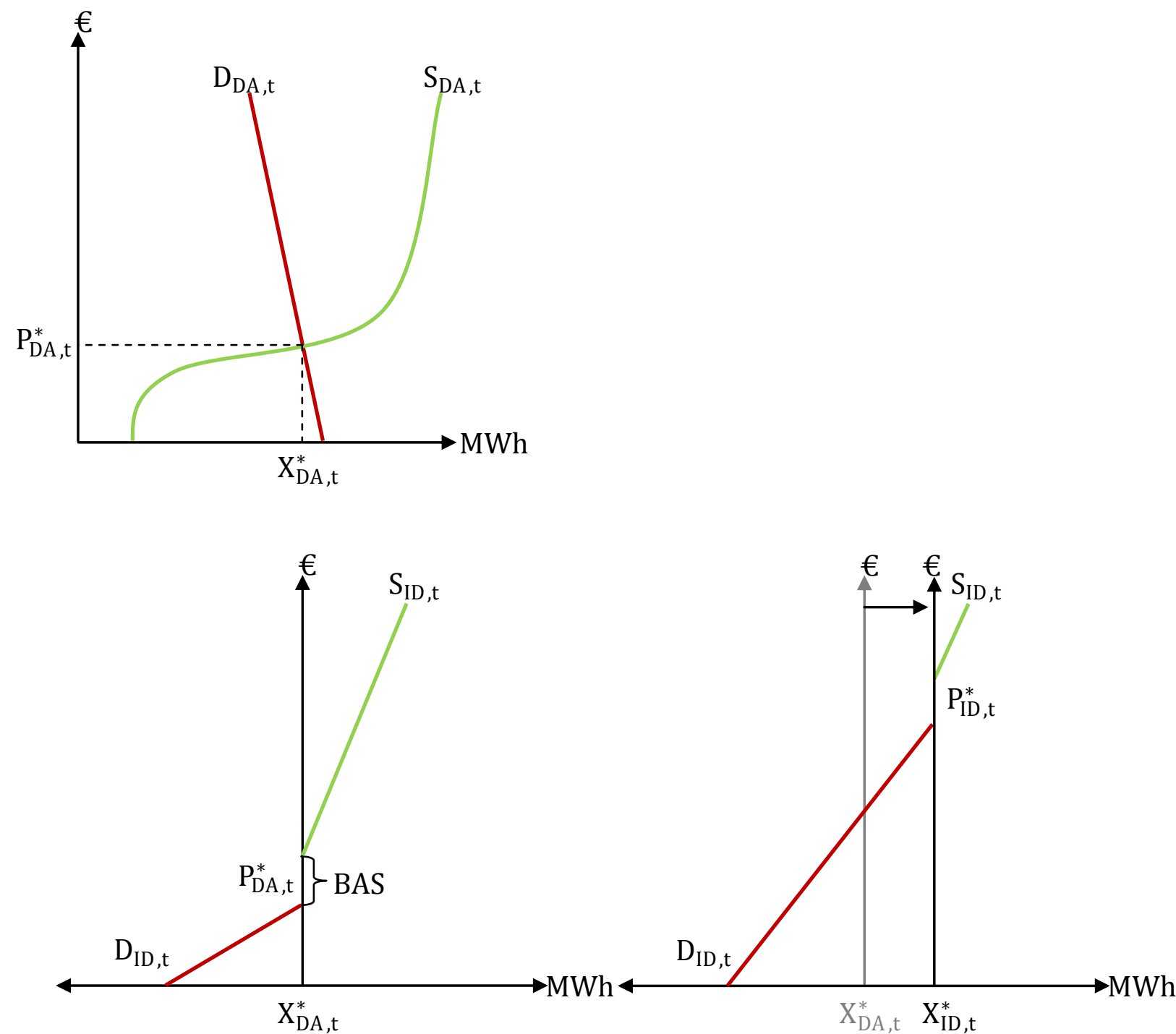

Figure I top: Day-ahead price formation for delivery hour $t$ through the matching of aggregated demand with the merit-order.

Down left: Intraday market opening without any information changes after the day-ahead gate closure.

Down right: Intraday increase of demand with new intraday price and demand equilibrium.

The hourly day-ahead price is the market clearing price of a one shot auction for each delivery hour of the day. The exchange aggregates all bids to a demand curve and all offers to a supply or merit-order curve. According to Hirschhausen et al. (2007) the merit-order reflects the marginal costs of all power plants which are offering electricity in the competitive day-ahead market. The day-ahead equilibrium price and market clearing quantity are then calculated by matching the aggregated demand and supply curves (Figure I top). The daily base-price is an average price of the 24 hourly equilibrium prices of a day.

Without any information changes between the day-ahead gate closure and the moment of physical delivery, the power plant from the day-ahead auction with marginal costs of $\mathrm{P}_{\mathrm{DA}, \mathrm{t}}^{*}$ would determine not only the hourly day-ahead price but also the hourly intraday price (figure 
I top and down left). ${ }^{7}$ The supply and demand reflects the fundamentally availably power plant capacities under certain restrictions. The supply (offers) on the intraday market would equal the sum of production capacity of flexible and unused power plants with marginal costs above the day-ahead price. Unused power plants which are being held in reserve to deliver positive balancing services will not offer electricity in the intraday market. The quantity of demand (bids) without any information changes between the day-ahead gate closure and the hour of physical delivery is determined by the quantity of operating power plants ${ }^{8}$ with downward flexibilities. Profit maximizing power plant operators will try to buy back energy in the intraday market at a price below the marginal costs of their operating power plants and ramp them down. The downward flexibility of base load plants is restricted by the power plant specific minimum load, as Nicolosi (2010) emphasizes. Furthermore must run capacities which operate to deliver heat or negative reserve power and power plants which operate to deliver negative balancing service will not be ramped down. Adapting the wording of patient and impatient traders in a limit order market by Foucault et al. (2005), power plant operators can be described as patient market participants, because they have the option but not the obligation to buy or sell electricity in the intraday market.

Initially, no trading can be observed because the cheapest unused power plant has higher marginal costs than the most expensive operating power plant. Thus, the supply curve lies above the demand curve and no optimization potential exists. In addition to the patient owners of upwards and downwards power plant flexibilities, a second group of intraday market participants with the obligation to trade in the intraday market appears. Unforeseen events after the day-ahead gate closure and before the moment of physical delivery push market participants to balance their portfolios and create additional demand and supply. These market participants can be named impatient traders, because they have a significant financial incentive to balance their portfolios in the intraday market. The current electricity market system is designed in a way that it is always the cheaper option to balance a portfolio on the intraday market than to buy balancing services from the TSO. ${ }^{9}$

\footnotetext{
${ }^{7}$ Hirschhausen et al. (2007) mention on p. 32 that not only power plant owners offer electricity in the day-ahead market but also electricity traders who wish to sell electricity they previously bought on long term markets. Hence, the equilibrium price in the day-ahead market may also be determined by those trading positions and deviate from the marginal costs of the marginal power plant.

${ }^{8}$ Under the premise that power plant operators strive for profit maximization, all operating power plants have marginal costs below the marginal price from the day-ahead auction and earn a profit margin that equals the shadow price.

${ }^{9}$ Until 2012, the balancing prices did not have their price floor above the intraday market price which set an economic incentive for market participants with imbalances not to trade in the intraday market in tight intraday market situations, because in those rare cases the balancing energy price was expected to be below the intraday market price. This market flaw has been removed in 2012 (BNA, 2012).
} 
Considering impatient and patient traders as the two main groups of actors in the intraday market, two market models where the market participants behave differently can be formulated. In the first one, the patient traders are power plant owners who trade in an atomistic market structure with perfect competition, zero transaction costs ${ }^{10}$ and perfect information availability. The impatient traders are all market participants with intraday imbalances and they are considered to become risk averse. In this setting, patient traders always offer all their available and flexible up- and down-ramping capacities at the power plant specific marginal costs in the limit order book of the intraday market because this strategy ensures profit maximization under the perfect competition assumption. A single power plant owner has no influence on the market price. The intraday demand and supply functions reflect only the fundamentally available power plant capacities. As a consequence of their risk-aversion, impatient traders do not wish to speculate with their intraday trading positions and close them immediately after they appear via sell- or buy-market orders. ${ }^{11}$ Only the fundamentally available upward- and downward-ramping capacities provide liquidity in the limit order book in this first model. Therefore, this model is named the fundamental model of liquidity.

In the second market model, the generation side is not perfectly competitive, e. g. with four dominant players and several small power plant owners who form the competitive edge. Significant transaction costs and imperfect information availability make intraday trading more complex and expensive. All market participants strive for profit maximization. The patient traders may offer their available and flexible up-and down-ramping capacities only partly via limit orders and at prices that ensure the coverage of the power plant specific marginal costs plus a profit margin. The dominance of big market participants is even increased by missing intraday office occupation of the small power plant owners and other market participants during weekends, holidays and nighttime. Thus power plant owners may exercise market power and influence the price. Impatient traders are less risk averse than in the fundamental model and try to increase their intraday trading profit and decrease their costs of immediate order execution against patient traders. In this case, impatient traders may enter buy or sell limit orders, thus increasing intraday liquidity provision, or wait until other impatient traders reveal their trading interest first and then execute a market order against them. Bodurtha and Quinn (1990) notice that this trading behavior can be observed in stock markets as well. Since the

\footnotetext{
${ }^{10}$ Transaction costs in the intraday market typically include exchange fees, employment costs of intraday managers and infrastructure costs like information technology development and purchase costs.

${ }^{11}$ The risk-averseness causes a utility loss from bearing the risk to hold an intraday trading position that always exceeds the utility gain from uncertain favorable market price development.
} 
trading behavior of all market participants influences the liquidity provision in the limit order book in the second market model, this model will be named the trading model of liquidity. The following key research question will be analyzed: Does the fundamental or the trading model of liquidity explain the liquidity provision in the GIME adequately? Because this research question is not empirically testable, model hypotheses that are empirically testable are derived in the following paragraphs. Hypotheses that are connected to the fundamental market model are labeled with (a) and hypotheses that are connected to the trading model are labeled with (b).

The dimensions of liquidity that are summarized in chapter 3.1 can be related to the two market models which have been described in the previous paragraph. When the GIME opens at three pm, the hourly bid-ask spread equals the difference between the cheapest flexible unused power plant with marginal costs above the day-ahead price $\left(b_{t}\right)$ and the most expensive and flexible operating power plant with marginal costs below the day-ahead price $\left(a_{t}\right)$.

$\mathrm{BAS}_{\mathrm{t}}=\mathrm{b}_{\mathrm{t}}-\mathrm{a}_{\mathrm{t}}$

As soon as impatient traders with portfolio imbalances appear in the market, the BAS is more and more determined by their trading behavior and limit order book dynamics. Under the assumptions of the fundamental market model, the impatient traders will execute their orders immediately and only against patient traders with power plant flexibilities. Thus the BAS may only increase with the total amount of deviations from the day-ahead planning. Under the assumptions of the second market model, impatient traders may try to optimize their execution price and maximize their order execution probability by entering limit orders within the prevailing BAS. Thus the size of the BAS may be negatively correlated with trading activity. This leads to the following hypotheses:

Hypothesis I a: The size of the BAS is positively correlated with intraday trading activity. Hypothesis I $b$ : The size of the BAS is negatively correlated with intraday trading activity.

Market resiliency has been defined as the rate at which prices in the limit order book bounce back to the competitive level after an uninformative liquidity shock from a sequence of market orders. Given the traders present in the market and the necessity of physical delivery, the 
occurrence of uninformed noise trading is rather unlikely in the GIME. ${ }^{12}$ Market participants trade only in order to close open positions or to optimize the short term operation of flexible power plants. Under the assumptions of the fundamental market model, a liquidity shock due to intraday information updates is being executed against fundamental power plant capacities in the limit order book. Given the assumption that all power plant flexibilities are incorporated in the limit order book, the prices cannot be resilient because the market liquidity is limited to the quantities available in the limit order book. Under the assumptions of the trading model, the prices may recover after a liquidity shock due to three reasons. Firstly, the remaining impatient traders may adjust their limit order prices to the new price level after a liquidity shock. Secondly, patient power plant owners who have not offered their power plant capacities previously might find it profitable enough to market the power plants at the new price level. Thirdly, information updates about deviations from the day-ahead planning appear and may be included by the impatient traders via limit orders into the limit order book as time passes by. This yields the hypotheses:

Hypothesis II a: The intraday market is not resilient.

Hypothesis II b: The intraday market is resilient.

The price impact and market depth dimensions of liquidity are determined by the slope of the intraday demand and supply curves. Under the assumptions of the fundamental market model, the slopes of both curves depend only on the fundamental demand and supply curves in the intraday market. Power plant owners offer their flexible and available upward- and downward-ramping capacities in the intraday market and all other market participants trade their imbalances as soon as they appear against the power plant owners. During delivery hours where the merit-order shape is inelastic (roughly for a residual demand ${ }^{13}$ below 30 Gigawatthours (GWh) and above $60 \mathrm{GWh})^{14}$ the intraday market demand and supply functions may be steep, leading to a low depth and a high price impact of a standardized trade. For a residual demand between approximately 30 and $60 \mathrm{GWh}$, the merit-order is elastic and has a rather flat slope. During those delivery hours the intraday demand and supply functions may have a flat slope as well and the market depth may be high. In this case, the price impact of a standar-

\footnotetext{
${ }^{12}$ Except maybe accidental mistrades which do not occur in significant quantities to be considered.

${ }^{13}$ Total demand corrected for imports and exports minus must-run capacities like renewable energy sources and power plants which supply heat.

${ }^{14}$ The figures are taken from Nicolosi (2010), who presents on page 7261 a scatterplot of all merit-order curves from October 2008 until November 2009. Note that the shape of the merit-order is variable and dependent on the capacity of power plants in revision or outages.
} 
dized trade may be low. Furthermore the market depth may decrease with an increasing volume of intraday deviations from the day-ahead planning under the assumptions of the first market model.

Under the assumptions of the trading model and at the time when the intraday market opens, it can be expected that the hourly intraday demand and supply functions have a steep (flat) slope and thus low (high) market depth during delivery hours where the merit-order is inelastic (elastic). But in contrast to the assumptions of the first market model, power plant owners may not offer all their available and flexible power plant capacities immediately, which may lead to a lower market depth and higher price impacts. Furthermore, the market depth and the slope of the demand and supply curves may be influenced by the total amount of intraday imbalances. As the aggregated amount of deviations from the day-ahead planning increases, market participants with open intraday positions may behave like patient traders and include limit orders into the order book, which decrease the slope of the intraday demand and supply functions and increase the market depth. Because the capacity retention of power plant owners and limit order trading of impatient market participants may have a counteracting effect on the market depth, it remains theoretically unclear which relation between market depth and the amount of deviations from the day-ahead planning exists under the assumptions of the trading model. Consequently the only hypothesis to be retained here is:

Hypothesis III a: The market depth is negatively correlated with intraday trading activity.

According to the assumptions of the fundamental market model, the price volatility per delivery hour may be determined by the slope of the demand and supply curves and hence by the slope of the underlying fundamental merit-order. The higher the slopes, the larger may be the price impact of a standardized trade and thus the difference of the trade price to the average price per delivery hour. Therefore, the price variance may be higher when the underlying merit-order is steep as indicated by extreme day-ahead prices. Under the assumptions of the trading model of liquidity, impatient traders who trade via limit orders may increase intraday liquidity and thus may decrease the slopes of the fundamental demand and supply functions. Therefore, price variance may still be positively correlated with extreme day-ahead prices according to the trading model, but the positive correlation may be weaker than under the assumptions of the fundamental model.

The correlation between price volatility and the total intraday adjustment need (trading volume) may be positive under the assumptions of the fundamental market model. For a mono- 
tonously increasing supply (decreasing demand) function, additional intraday demand (supply) may be satisfied by power plants with higher (lower) marginal costs. In other words trading activity from impatient traders may consume liquidity which is provided by power plant owners and decrease market depth. According to the trading model, impatient market participants may behave like patient traders in order to increase their revenues and trade with limit orders, thus increasing liquidity in the limit order book. The intraday imbalances of different market participants may be complementary and offset each other without large effects on the price, if the market participants trade via limit orders. Concluding, the price variance may be increased by trading volume under the assumptions of the trading model, but the positive influence may be weaker than under the assumptions of the fundamental model.

Hypothesis IV a: Price variance is positively correlated with extreme day-ahead prices. Hypothesis IV b: Price variance is weakly positively correlated with extreme day-ahead prices.

Hypothesis V a: Price variance is positively correlated with intraday trading activity. Hypothesis V b: Price variance is weakly positively correlated with intraday trading activity.

Search and delay costs can be expected to be significant in the intraday market. The fundamental merit-order based liquidity in the intraday market comes along with a comparably large BAS and low market depth, making immediate trading expensive. ${ }^{15}$ As time passes by, more and more information about deviations from the day-ahead planning enter the intraday market and may be incorporated into the limit order book, leading to a smaller BAS, a large market depth and comparably flat demand and supply curves. Under the assumptions of the fundamental model, the risk costs to hold a position always outweigh the benefit of a wait and see strategy, even though a market participant may decrease the BAS- and market impactcosts by delaying a trade from the moment when an imbalance occurs until the time shortly (approximately two hours) before delivery. According to the trading model, the market participants are less risk averse and try to maximize their intraday profits through trading strategies. Thus, they face a trade-off between (1) closing an intraday imbalance immediately at low search and delay costs and comparably high BAS and market impact costs or (2) wait until more information are incorporated in the intraday market and bear the associated search and delay costs.

\footnotetext{
${ }^{15}$ The observed BAS when the GIME opens at three p. m. often amounts to 16-20 euro.
} 
Trading activity is defined as the hourly trading volume and the hourly number of trades. Without any information changes between the day-ahead gate closure and the hour of delivery, demand and supply would match perfectly according to the day-ahead planning and the intraday trading activity would be zero as no economical reason for intraday adjustments exists. The need for intraday trading arises due to changes of demand or supply of electricity after the day-ahead gate closure. Thus, the trading activity may equal the intraday adjustment needs under the assumptions of both market models. Under the assumptions of the fundamental market model, intraday deviations are being traded as soon as they become apparent for a market participant. Thus, each type of deviation from the day-ahead planning may influence the indicators of liquidity similarly.

Under the assumptions of the trading model, even the impatient traders with portfolio imbalances may behave like patient traders and may decide not to trade imbalances immediately in the GIME. In this case, counteracting imbalances within one portfolio may offset each other, leading to a reduced trading quantity of each impatient market participant and also to reduced market impacts of the intraday deviations from the day-ahead planning. Therefore, the indicators of liquidity may not be influenced equally by each deviation from the day-ahead planning under the assumptions of the trading model.

Hypothesis VI $a$, $b$ : Intraday trading volume and the number of trades are determined by the intraday deviations from the day-ahead planning.

Hypothesis VII a: All deviations from the day-ahead planning have a similar impact on the indicators of liquidity.

Hypothesis VII b: The various deviations from the day-ahead planning have different impacts on the indicators of liquidity.

\subsection{Further factors affecting intraday liquidity and trading}

The theoretical liquidity provision by patient power plant owners is complemented by the liquidity consumption of impatient traders who trade their intraday deviations from the dayahead planning to correct their schedules. The total intraday adjustment need is the sum of intraday demand and supply due to power plant outages, wind forecast errors, solar power forecast errors, load forecast errors, trading volumes from foreign demand and supply, combined heat and power plant (CHP) optimizations and intraday trading positions. Furthermore, time of the day and day of the week effects may influence liquidity. 
Intraday demand may be created by unplanned power plant outages. Electricity from defaulting power plants which was previously sold on long term or day-ahead markets has to be replaced by the seller in order to fulfill his contractual commitments. However shortages due to unplanned outages will only partly lead to purchases on the intraday market. If a power plant defaults before the day-ahead gate closure at $12 \mathrm{am}$, it's delivery for the next day can be substituted by purchases in the day-ahead market. Thus, the missing electricity production until the end of the day has to be purchased on the intraday market. If a power plant defaults after the day-ahead gate closure, the electricity production for the current and the next day has to be replaced by purchases on the intraday market. From the day after tomorrow on the power plant will be substituted by purchases on the day-ahead market.

Renewable energy sources already account for a substantial part of the German power plant fleet. By the end of 2011 the installed capacity of intermittent RES accumulated to almost 54 GW (Windmonitor, 2012; Bundesverband Solarwirtschaft, 2012). ${ }^{16}$ From January 2010 until December 2011, the four TSOs almost exclusively marketed the expected production from RES (Ullrich, 2009). Therefore, the production profile from RES for the next day was estimated with forecast models and sold limitless on the day-ahead market. In general, the forecast's preciseness is greater, the closer the forecasted time horizon lies. Hence, the intraday forecast for the production of RES showed deviations from the day-ahead forecasts. The TSOs may trade the quantity variance in their portfolios resulting from differences between the day-ahead and the comparably smaller intraday forecast error of wind and solar power plants on the intraday market. ${ }^{17}$

The DENA (2010) and Haubrich (2008) define the load forecast error as the deviation of the per-quarter-hour mean load value from the forecasted load value. Short term load forecasting is performed by all German balance group responsible parties to predict the future level of electricity demand and is important for a proper supply and demand side planning. The deviation of the actually realized load from the day-ahead planned load may be traded in the intraday market. Because there are no grid-wide load forecasts being performed in Germany, figures about the total load forecast errors are difficult to estimate but load forecasts can be ex-

\footnotetext{
16 The total capacity of installed RES can be divided into wind power (29.012 MW) and solar power (24.800 MW).

${ }^{17}$ The forecast error can be measured as the capacity-weighted root mean square error (RMSE) of the wind and solar power production. In the sample period 2010 to 2011 used in this paper RMSE values for wind and PV power of $3.59 \%$ and $2.11 \%$ in 2010 and $3.60 \%$ and $3.02 \%$ in 2011 respectively have been calculated. The RMSE is calculated with respect to the installed capacity and not to the actual power production of the RES. Assuming 1600 full load hours for wind power and 900 full load hours for PV power, the average day-ahead prediction error for wind and PV power is $19.66 \%$ and $20.53 \%$ in 2010 and $19.71 \%$ and $29.39 \%$ in 2011.
} 
pected to be quite precise because the forecasting models can be adjusted on a long data history. ${ }^{18}$

Germany is well connected to its neighboring countries. The ENTSOE reported net transfer capacity (NTC) of 16585 MW in 2011 for imports into Germany and 15280 MW for exports respectively. According to the ETSO (2007), NTCs which have not been used in day-ahead or long term auctions are freely available for intraday cross border trading. Lehmann et al. (2012) give an overview of the increase of RES in bordering countries like Demark, the Netherlands, France and the Czech Republic in the last years. The increased capacity of installed RES might lead to an increased demand for intraday optimizations and hence raise intraday export and import volumes resulting from foreign RES-E forecast errors. For the case of Denmark Jorgensen and Ropenus (2008) confirm that generation adequacy is ensured in many cases through cross border intraday trading. The French TSO RTE requests balancing services from German counterparts which are then being traded in the GIME. ${ }^{19}$ Intuitively, the coupling of electricity markets is expected to foster liquidity pooling and competition as the number of active market participants and fundamentally explainable demand and supply of electricity increases. During the time frame which will be considered here from 2010 to 2011, only French market participants traded directly on the GIME. Hence, only the French trades on the GIME will be considered.

Time of the day and day of the week effects may have an impact on intraday liquidity. Offpeak hours are the hours from midnight to eight a. m. and from eight p. m. to midnight and may show a lower intraday liquidity than the peak hours. This time of the day effect may be caused by different factors. Firstly, the electricity demand is lower during the night. Under the assumption of a constant relative load forecast error, the lower load may lead to lower load forecast errors. Thus, the TSOs may trade lower quantities from load forecast errors during the off-peak periods. Secondly, solar power plants produce no electricity during the off-peak periods. Thus, no forecast errors from solar power will be traded at night. Thirdly, the benefits from employing a shiftteam for the off-office hours and the weekends may not outweigh the costs in companies with small generation or customer portfolios. Those companies close their intraday positions for the night and the weekend during the usual office hours. New intraday positions which occur during off-office hours will usually not be traded on the intraday mar-

\footnotetext{
${ }^{18}$ For the year 2007, Haubrich (2008) calculated a load forecast error for all four Germany control areas with an average of $225 \mathrm{MW}$ and a standard deviation of $1154 \mathrm{MW}$ (1.46\% of the annual peak load). Another analysis (DENA, 2010) calculated a day-ahead load forecast error for the period from October 2006 to September 2007 which was normally distributed with a mean value of $53.56 \mathrm{MW}$ and a standard deviation of $644.67 \mathrm{MW}(0.8 \%$ of the annual peak load).

${ }^{19}$ An analysis of activated balancing services is published monthly on the RTE homepage (RTE, 2012).
} 
ket (exceptions may be severe events like power plant outages) but will be compensated by balancing services.

Day of the week effects may also influence liquidity in the GIME, because small electricity companies may not employ shift teams for intraday trading during the weekend. A lower number of market participants may lead to lower trading activity and less market efficiency on Sundays and Mondays (some deviations for Saturday may still be traded on Friday).

CHP plants follow peculiar intraday optimization logics which may lead to purchases and sales in the intraday market. CHP plants increase fuel efficiency by producing electricity and heat for industrial processes or district heating. In Germany, 19,243 MW of electrical power plant capacity are cogenerating units according to an overview of the UBA (2013). ${ }^{20}$ Even if only a share of all CHP plants is operating, they may have a significant influence on intraday liquidity. The dispatch planning focuses on the satisfaction of the forecasted heat demand. The electrical output is treated as a by-product and can be optimized intraday. With increasing heat demand, CHP plants show limited power production flexibility as illustrated by Ummels et al. (2007) or Ellersdorfer et al. (2008). Still, if the required heat output is given for a delivery hour, the power output is variable and may be optimized intraday.

Finally trading positions may have increased the intraday liquidity in Germany. Until November 2011, market participants could buy or sell energy in the day-ahead auction and transfer the resulting long or short position into the intraday market in Germany to benefit from expected price differences between the day-ahead and intraday market as noticed by the ETSO (2007). Those intraday positions had to be closed before the hour of physical delivery, leading to increased intraday trading. The quantification of the total long and short trading positions of all market participants is impossible, because the creation of trading positions will probably be a subject of trader specific market expectations. Therefore, trading positions cannot be considered explicitly.

\section{EMPIRICAL ANALYSIS}

\subsection{Data}

Data cover the period from January $1^{\text {st }} 2010$ to December $31^{\text {st }} 2011$ and stem from a variety of sources. Wind and solar day-ahead forecasts and the realized infeed are collected from the websites of the four TSOs and the common online platform www.eeg-kwk.net/de. The hourly

\footnotetext{
${ }^{20}$ Power plants with an electric output above $100 \mathrm{MW}$ and a heat output which reaches at least $50 \%$ of the electrical output are being considered.
} 
average is calculated from the data which is available per quarter of an hour. Concerning the solar day-ahead forecast and infeed, data is missing completely or partly for all four TSOs in 2010 , because the publication of such data is only obligatory, if the installed solar capacity exceeds a certain threshold. The day-ahead prices, intraday prices, transaction lists and trading volumes are provided by the EPEX Spot and EEX. A yearly profile of the total unplanned hourly outage capacity with relevance for intraday trading is calculated from the unplanned outages data provided by the EEX.

\subsection{Construct measurement}

The theoretical complexity of the liquidity construct motivated a research stream which focused on the development of methods to accurately measure liquidity over long and short time periods (see Bessembinder and Kaufman, 1997; Corwin and Schultz, 2012; Goyenko et al., 2009; Korajczyk and Sadka, 2008; Marshall et al., 2012). Those measurement methods cannot be applied with the available data from the intraday market. Resiliency and the price impact cannot be measured because the required order book data is currently not being recorded in the GIME. The measurement of delay and search costs is not feasible because they are determined by the individual decision process of each trader, his deviations from the day-ahead planning and his market analysis. Therefore we subsequently focus on the liquidity indicators shown in Figure II.

The BAS is usually being measured via the effective or quoted spread. The calculation of both measures requires order book data about the prevailing BAS while a trade was executed which is not yet being recorded in the GIME. Instead the BASis calculated with transaction data. All trades in the yearly transaction list are sorted in a chronological row according to their time stamp. Afterwards, the tick test algorithm of Lee and Ready (1991) is employed to define each trade as a "buy" or a "sell". Every time two chronologically subsequent buy and sell trades appear, the difference between both trade prices is calculated and used as one BAS figure. Finally, all spreads for an hour are used to calculate the average BAS of that hour. This procedure shows two weaknesses. The first one stems from the tick test's error rate of 1.2 $47.6 \%$ when classifying a trade as a buy or a sell. The second weakness is the algorithms tendency to underestimate the magnitude of the true BAS.

Price volatility is measured using the high to low difference. The difference between the highest and the lowest trade price for a delivery hour reflects the maximum price spread and thus price variability. 
$\tau_{\mathrm{t}}=\left(\mathrm{P}_{\mathrm{H}, \mathrm{t}}-\mathrm{P}_{\mathrm{L}, \mathrm{t}}\right)$

Furthermore price volatility is calculated as the average price variance of all trades for one delivery hour. The index $n$ denotes the single trades for one delivery hour $t$.

$\sigma_{t}^{2}=\frac{1}{n} \sum_{1}^{n}\left(x_{n, t}-\bar{x}_{t}\right)^{2}$

Trading activity is measured via the trading volume in MWh and the number of trades determined as the number of trades per delivery hour.

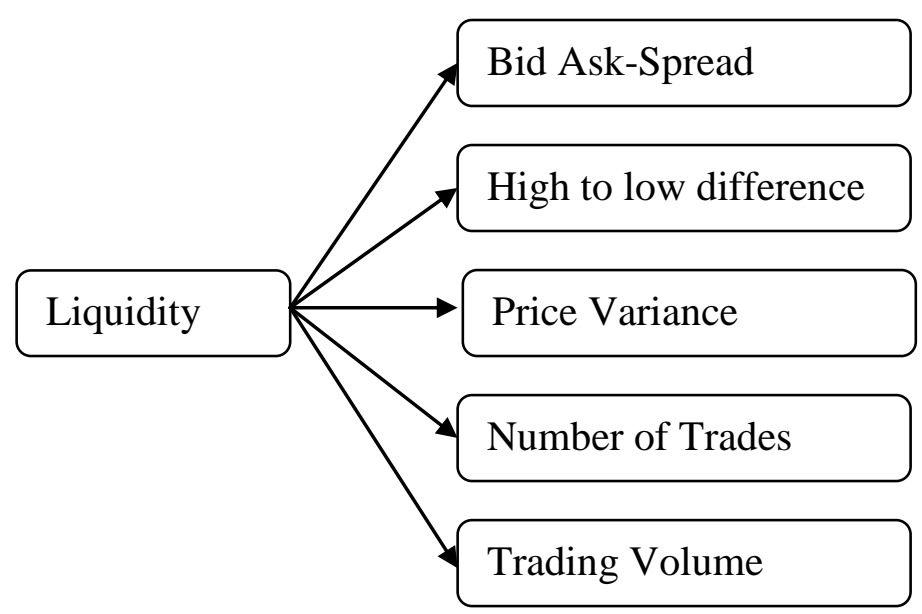

Figure II: Considered dimensions of liquidity.

The time of the day- and day of the week-effects are measured with dummy or binary variables. Wooldridge (2011) explains that the difference in the dependent variable (while all other independent variables are fixed) between a specific group and the reference group can be estimated by employing dummy variables. The periods peak (time from eight a. $\mathrm{m}$. to eight p. m.) and Wednesday are taken as the reference groups and thus omitted in the empirical results.

To create a time series for the analysis of the influence of extreme day-ahead prices on the liquidity indicators, the squared difference between the hourly day-ahead price and the average day-ahead price in 2010 and 2011 of $47.81 € / \mathrm{MWh}$ is calculated.

\subsection{Empirical results}

In chapter 3.2 and 3.3, the fundamental merit-order, the trading behavior and intraday deviations from the day-ahead planning have been identified as theoretical determinants of liquidity 
in the GIME - with partly diverging effects on the different dimensions of liquidity. In the empirical investigation, the correlations between the dimensions of liquidity as well as the influence of deviations from the day-ahead planning on each dimension of liquidity will be analyzed. In five regression analyses the average BAS, high to low difference, variance, trading volume or the number of trades will be considered as endogenous variables together with the explanatory variables power plant outages, differences between day-ahead and intraday forecasts of renewable energy sources, French trades in the GIME, merit-order shape effects, time of the day and day of the week effects.

The descriptive statistics of the liquidity indicators are summarized in table I. The calculated average BAS equals almost $3 € / M W h$ which is large compared to the continuous day-ahead trading where the usual spread is $0.25 € / \mathrm{MWh}$ as the delivery period approaches. The minimum values indicate that some hours show almost no trading, for example where the number of trades is one. Also remarkable is the high price volatility which is reflected by the average variance of 42.62 and an average difference between the highest and lowest price of 24.65 $€ / \mathrm{MWh}$. The trading volume increased significantly compared to previous years. It was 10.3 Terawatt hours (TWh) in 2010 and 16.6 TWh in 2011 which equals an average of $1536 \mathrm{MW}$ per delivery hour over2010 and 2011.

Table I: Descriptive statistics of the liquidity indicators.

\begin{tabular}{llllllll}
\hline & $\mathbf{N}$ & Minimum & Maximum & Average & $\begin{array}{l}\text { Standard } \\
\text { Deviation }\end{array}$ & Skewness & Kurtosis \\
\hline $\begin{array}{l}\text { Average BAS } \\
(€)\end{array}$ & 17377 & 0.05 & 64 & 2.97 & 2.58 & 6.1 & 77.8 \\
$\begin{array}{l}\text { High to Low } \\
\text { Difference (€) }\end{array}$ & 17508 & 0 & 735 & 24.65 & 28.05 & 11.95 & 226.7 \\
$\begin{array}{l}\text { Variance } \\
\text { Number of }\end{array}$ & 17418 & 0.01 & 8829.07 & 42.62 & 195.22 & 26.12 & 870.07 \\
$\begin{array}{l}\text { Nudes } \\
\text { Trading vo- }\end{array}$ & 17444 & 1 & 234 & 43.23 & 26.47 & 1.28 & 2.21 \\
$\begin{array}{l}\text { Tume (MWh) } \\
\text { lume }\end{array}$ & 17508 & 20 & 8385 & 1536.42 & 1119.79 & 1.82 & 4.45 \\
\hline
\end{tabular}

The bivariate Pearson-correlations between the considered indicators of liquidity are summarized in table II. To control for the influence of the number of actively trading market participants, the correlations were calculated with the residual time series of the indicators of liquidity from the regression analysis. In the regression analysis, the number of actively trading market participants is implicitly controlled for through the time of the day and day of the week dummies, because the number of market participants is lower during the weekend as 
well as duringoff-peak one and two periods. ${ }^{21}$ The correlations between the original time series are presented in parentheses. The correlation between the average BAS and trading activity becomes insignificant or slightly positive after controlling for the number of actively trading market participants while all other correlations change only slightly. The number of trades and trading volume are highly correlated (0.693) thus indicating that both indicators capture the construct trading activity. Also the two volatility indicators price variance and high to low differencehave a considerable positive correlation (0.470). The correlation between the volatility indicators and the BAS is almost as high (0.439 resp. 0.426).

These results suggest that there are in fact three empirically observable liquidity dimensions, which are rather distinct from one another. The first liquidity dimension is tightness as measured by the BAS. The second observable liquidity dimension is price volatility which is to some extent linked to the first dimension. The third observable dimension, trading activity is however almost independent from the first two dimension.

Table II: Bivariate Pearson-correlations between the indicators of liquidity after controlling for determinants of liquidity. The correlations between the original time series of the indicators of liquidity are included in parenthesis. (*) denotes two-sided significance on the 0.01 level.

\begin{tabular}{|c|c|c|c|c|c|}
\hline & AVG BAS & $\begin{array}{l}\text { High to Low } \\
\text { Difference }\end{array}$ & Variance & $\begin{array}{l}\text { Number of } \\
\text { Trades }\end{array}$ & $\begin{array}{l}\text { Trading Vo- } \\
\text { lume }\end{array}$ \\
\hline \multirow{2}{*}{ AVG BAS } & 1 & & & & \\
\hline & 1 & & & & \\
\hline \multirow{2}{*}{$\begin{array}{l}\text { High to low dif- } \\
\text { ference }\end{array}$} & $.439 *$ & 1 & & & \\
\hline & $\left(.438^{*}\right)$ & 1 & & & \\
\hline \multirow{2}{*}{ Variance } & $.426 *$ & $.470 *$ & 1 & & \\
\hline & $(.439 *)$ & $(.494 *)$ & 1 & & \\
\hline \multirow{2}{*}{$\begin{array}{l}\text { Number of } \\
\text { Trades }\end{array}$} & .000 & $.233^{*}$ & $.130 *$ & 1 & \\
\hline & $(-.117 *)$ & $(.237 *)$ & $(.100 *)$ & 1 & \\
\hline \multirow{2}{*}{ Trading Volume } & $.031 *$ & $.197 *$ & $.108 *$ & $.693 *$ & 1 \\
\hline & $(-.068 *)$ & $(.228 *)$ & $(.101 *)$ & $\left(.813^{*}\right)$ & 1 \\
\hline
\end{tabular}

The overall regression results are summarized in table III. The model results show adjusted $\mathrm{R}$ square values of 0.5519 for the number of trades and 0.4522 for the trading volume. The average BAS, high to low difference and the price variance show lower adjusted R square values below 0.1 . Nevertheless, the overall model statistics indicate significance beyond the $1 \%$ error threshold which indicates that relevant relationships between the dependent and independent variables have been found and the predictive power of all models goes beyond pure guessing.

\footnotetext{
${ }^{21}$ The subsequent regression analysis also controls for other determinants but the day of the week and time of the day effects. Nevertheless, controlling only for the day of the week and time of the day effects does not change the correlations between the residual time series of the indicators of liquidity.
} 
The Durbin-Watson statistics are between 0.33 and 1.41 thus indicating positive autocorrelation in the residuals. Positive autocorrelation in the residuals may lead to biased standard errors if the regression model is estimated with the ordinary least squares method. Petersen (2008) recommends calculating more robust standard errors with the Newey-West procedure.

Table III: Summary statistics regression models.

\begin{tabular}{llllll}
\hline & $\begin{array}{l}\text { AVGBAS } \\
(\boldsymbol{€})\end{array}$ & $\begin{array}{l}\text { High to } \\
\text { Low Differ- } \\
\text { ence }(\boldsymbol{\epsilon})\end{array}$ & Variance & $\begin{array}{l}\text { Number of } \\
\text { Trades }\end{array}$ & $\begin{array}{l}\text { Volume } \\
(\mathbf{M W h})\end{array}$ \\
\hline R Square & 0.0901 & 0.0691 & 0.0461 & 0.5523 & 0.4526 \\
\hline Adjusted R Square & 0.0895 & 0.0684 & 0.0454 & 0.5519 & 0.4522 \\
Standard Error of Regression & 2.46 & 27.08 & 190.75 & 17.72 & 828.82 \\
\hline F Statistic & 132.3 & 99.85 & 64.64 & 1653.68 & 1112.47 \\
Model Significance & $<0.005$ & $<0.005$ & $<0.005$ & $<0.005$ & $<0.005$ \\
\hline Durbin-Watson Statistic & 1.41 & 0.71 & 1.11 & 0.60 & 0.33 \\
\hline Observations & 17376 & 17506 & 17417 & 17443 & 17507 \\
\hline
\end{tabular}

The variance inflation factors (VIF) are between 1.14 and 12.04 but only one VIF exceeds a critical value of 10 . Thus, multicollinearity might bias the variances of the slope estimators of the regression models in a few cases. Following the recommendations by Wooldridge (2011), we do not eliminate any variables because the size of the VIF also depends on the total sum of squares which is increased by the sample size of more than 17300 observations in this study.

The unstandardized regression coefficients are summarized in table IV. Except the day of the week-dummies Saturday, Thursday and Friday, all independent variables have significant influences on at least one indicator of liquidity. The regression coefficients of the French trading volume, solar and wind forecast errors and outages are small in absolute size, because they capture the impact of a one MWh change of the independent variable on the indicators of liquidity. 
Table IV: Regression coefficients of the independent variables on the five liquidity proxies. (***) symbolizes significance at the 0.01 level, $(* *)$ at the 0.05 level and $\left(^{*}\right)$ at the 0.1 level. Unlabeled factors are insignificant. The t-values are reported in parentheses. Because the coefficients are not standardized, the dimensions are mentioned in the first row.

\begin{tabular}{|c|c|c|c|c|c|}
\hline & $\operatorname{AVGBAS}(€)$ & $\begin{array}{l}\text { High to Low } \\
\text { Difference }(€)\end{array}$ & Variance & $\begin{array}{l}\text { Number of } \\
\text { Trades }\end{array}$ & $\begin{array}{l}\text { Volume } \\
\text { (MWh) }\end{array}$ \\
\hline \multirow[t]{2}{*}{ INTERCEPT } & $2.0294 * * *$ & $12.7229 * * *$ & -14.9232 & $33.0746 * * *$ & $781.5436 * * *$ \\
\hline & (19.09061) & $(11.33243)$ & $(-1.16128)$ & $(20.06003)$ & $(10.33064)$ \\
\hline \multirow[t]{2}{*}{ VOLUME FRANCE } & $-0.0004 * * *$ & $0.0089 * * *$ & $-0.0218 * *$ & $0.0611 * * *$ & $1.8616^{* * *}$ \\
\hline & $(-4.05526)$ & (3.698188) & $(-2.487325)$ & (28.89782) & (16.16574) \\
\hline \multirow[t]{2}{*}{ VOLUME PV } & -0.00004 & 0.0005 & 0.0062 & $0.0059 * * *$ & $0.1798 * * *$ \\
\hline & $(-0.853457)$ & $(1.056123)$ & $(0.847113)$ & $(3.113765)$ & $(3.414609)$ \\
\hline \multirow[t]{2}{*}{ VOLUME WIND } & $0.0001 * *$ & $0.0036 * * *$ & $0.0185 * * *$ & $0.0079 * * *$ & $0.5091 * * *$ \\
\hline & (2.429196) & $(6.173751)$ & $(2.982564)$ & $(13.32031)$ & $(16.49313)$ \\
\hline \multirow[t]{2}{*}{ OUTAGES } & $0.0001 * *$ & $0.0019 * * *$ & $0.008 * *$ & $0.001 * *$ & $0.1308 * * *$ \\
\hline & $(2.164541)$ & $(3.613125)$ & $(2.394813)$ & $(2.051965)$ & (3.678059) \\
\hline \multirow[t]{2}{*}{$\begin{array}{l}\text { MERIT-ORDER } \\
\text { EXTREMES }\end{array}$} & $0.001 * * *$ & $0.0157 * * *$ & $0.1003 * * *$ & $0.0049 * * *$ & 0.0175 \\
\hline & $(8.004444)$ & (7.13967) & $(3.795237)$ & $(5.79466)$ & $(0.569013)$ \\
\hline \multirow[t]{2}{*}{ OFF-PEAK I } & $1.2441 * * *$ & 0.5023 & $13.6258 * *$ & $-16.5386^{* * * *}$ & $-515.7078 * * *$ \\
\hline & $(16.87482)$ & $(0.534143)$ & $(2.357907)$ & $(-14.84568)$ & $(-13.63536)$ \\
\hline \multirow[t]{2}{*}{ OFF-PEAK II } & $0.3782 * * *$ & $1.8042 * * *$ & $8.275^{*}$ & $-4.0675 * * *$ & -0.5533 \\
\hline & $(7.458524)$ & $(2.997581)$ & $(1.766599)$ & $(-3.225182)$ & $(-0.014513)$ \\
\hline \multirow[t]{2}{*}{ SATURDAY } & -0.0104 & 3.9076 & 5.517 & -1.704 & 55.4934 \\
\hline & $(-0.088166)$ & $(0.990029)$ & $(0.782649)$ & $(-1.183012)$ & $(0.646593)$ \\
\hline \multirow[t]{2}{*}{ SUNDAY } & $0.4651 * * *$ & 1.3761 & 7.8849 & $-8.3781 * * *$ & -98.6509 \\
\hline & (3.669617) & (1.064968) & (1.151818) & $(-6.500759)$ & $(-1.067564)$ \\
\hline \multirow[t]{2}{*}{ MONDAY } & $0.5312 * * *$ & $2.3921 *$ & 9.9395 & $-7.1387 * * *$ & -105.4207 \\
\hline & (3.861306) & (1.784223) & $(0.790337)$ & $(-5.375734)$ & $(-1.348444)$ \\
\hline \multirow[t]{2}{*}{ TUESDAY } & 0.1879 & $2.9526^{* *}$ & 10.1042 & 0.1321 & 62.3557 \\
\hline & (1.578712) & $(2.550046)$ & $(1.279953)$ & $(0.10194)$ & $(0.892831)$ \\
\hline \multirow[t]{2}{*}{ THURSDAY } & -0.1243 & -0.8442 & -3.223 & -0.2963 & 19.5137 \\
\hline & $(-1.186619)$ & $(-0.766167)$ & $(-0.51508)$ & $(-0.240495)$ & $(0.308586)$ \\
\hline \multirow[t]{2}{*}{ FRIDAY } & -0.0214 & 0.2527 & -0.7439 & -0.3451 & 25.5641 \\
\hline & $(-0.195941)$ & $(0.227592)$ & $(-0.13281)$ & $(-0.250034)$ & $(0.335304)$ \\
\hline
\end{tabular}

\subsection{Discussion}

The working hypotheses for the fundamental and the trading model of liquidity in the GIME are summarized in tables $\mathrm{V}$ and VI. 
Table V: Overview of hypotheses of the fundamental model of intraday liquidity.

\begin{tabular}{|l|l|l|}
\hline & Hypotheses fundamental model of intraday liquidity & $\begin{array}{l}\text { Con- } \\
\text { firmed? }\end{array}$ \\
\hline & $\begin{array}{l}\text { In the GIME, the fundamental model of liquidity explains the liquidity provi- } \\
\text { sion. }\end{array}$ & No \\
\hline H I $a$ & The size of the BAS is positively correlated with intraday trading activity. & No \\
\hline H II $a$ & The intraday market is not resilient. & No \\
\hline H III $a$ & The market depth is negatively correlated with intraday trading activity. ${ }^{22}$ & - \\
\hline H IV $a$ & Price variance is positively correlated with extreme day-ahead prices. & Yes \\
\hline H V a & Price variance is positively correlated with intraday trading activity. & Yes \\
\hline H VI $a, b$ & $\begin{array}{l}\text { Intraday trading volume and the number of trades are determined by the } \\
\text { intraday deviations from the day-ahead planning. }\end{array}$ & Yes \\
\hline H VII $a$ & $\begin{array}{l}\text { All deviations from the day-ahead planning have a similar impact on the in- } \\
\text { dicators of liquidity. }\end{array}$ & No \\
\hline
\end{tabular}

Table VI: Overview of hypotheses of the trading model of intraday liquidity.

\begin{tabular}{|l|l|l|}
\hline & Hypotheses trading model of intraday liquidity & $\begin{array}{l}\text { Con- } \\
\text { firmed? }\end{array}$ \\
\hline & In the GIME, the trading model of liquidity explains the liquidity provision. & Yes \\
\hline$H ~ I b$ & The size of the BAS is negatively correlated with intraday trading activity. & Yes \\
\hline$H ~ I I ~ b$ & The intraday market is resilient. & Yes \\
\hline$H \mathrm{IV} a$ & Price variance is weakly positively correlated with extreme day-ahead prices. & Yes \\
\hline $\mathrm{H} \mathrm{V} b$ & Price variance is weakly positively correlated with intraday trading activity. & Yes \\
\hline $\mathrm{H} \mathrm{VI} a, b$ & $\begin{array}{l}\text { Intraday trading volume and the number of trades are determined by the } \\
\text { intraday deviations from the day-ahead planning. }\end{array}$ & Yes \\
\hline $\mathrm{H} \mathrm{VII} b$ & $\begin{array}{l}\text { The various deviations from the day-ahead planning have different impacts } \\
\text { on the indicators of liquidity. }\end{array}$ & Yes \\
\hline
\end{tabular}

The correlations of the BAS with the number of trades (0.00) and trading volume (0.031) are insignificant or close to zero when controlling for common influencing factors like the number of actively trading market participants. Thus, the average BAS and trading activity seem to be two nearly independent dimensions of liquidity, which may rather be influenced by the number of actively trading market participants. This assumption is supported by the results of the regression analysis. The trading activity (average BAS) is significantly decreased (increased) during times of missing office occupation of small market participants which is the

\footnotetext{
${ }^{22}$ Not testable with the currently available data.
} 
case during the off-peak one and -two and on Sundays. These empirical findingsstand in contrast to previous results from studies for stock markets. Several authors like Amihud and Mendelson (1986) or Copeland and Galai (1983) report negative correlations between the BAS and trading volume or the number of trades. Further research in stock markets may focus on the question, whether it is rather the number of actively trading market participants and not the trading volume or the number of trades which has a decreasing effect on the BAS. With respect to the testing of the hypothesis $I \mathrm{a} / \mathrm{b}$ it can be concluded that trading activity, defined as the number of trades and trading volume, is not or positively correlated with the average BAS. Nevertheless, the average BAS seems to be negatively influenced by the number of market participants thus indicating that trading influences the BAS as expected according to hypothesis I b. Thus, hypothesis I b is not rejected but hypothesis I a.

The correlations between trading activity and the volatility indicators are small but significantly positive with values between 0.108 and 0.233 . There are no reference values for the impact of trading activity on the volatility indicators under the assumptions of the fundamental or the trading model. Yet the rather small size of the correlations is an indication that increased trading volumes dampen price volatility as more market participants trade via limit orders. Thus the correlations rather give support for the trading model (hypothesis V b) according to which the limit order trading of impatient market participants may lower the slopes of intraday demand and supply functions and thus reduce volatility. Nevertheless, hypothesis $\mathrm{V}$ a cannot be rejected, especially since the results of the regression analysis show that the price variance and high to low difference are significantly increased by wind forecast errors and outages. For a $1000 \mathrm{MW}$ increase of the wind forecast error, the high to low difference is increased by $3.6 € / \mathrm{MWh}$ and the variance by 18.5 .The variance reduction of -21.8 per Gigawatthour of French trading volumes may be due to the market participation of patient French traders who offer their available power plant capacities in the French intraday market which is implicitly coupled to the GIME. Thus, the patient French traders may decrease the slopes of the demand and supply functions and thus reduce the price variance.

The significantly positive correlations between the average BAS and high to low difference (0.439) and the BAS and price variance (0.426) indicate that increased price volatility tends to increase the BAS. According to the fundamental model, perfect competition forces power plant owners to offer all power plant flexibilities at marginal costs in the intraday limit order book. Thus, the liquidity provision by patient power plant owners is independent of the price volatility according to the fundamental model. In line with this assumption, short-run volatility due to liquidity shocks seems to consume liquidity instead of attracting additional liquidity 
which may in turn decrease short run volatility and the BAS and make the intraday market resilient. The significantly positive influence of wind forecast errors and outages on the average BAS, the high to low difference and price volatility in the regression analysis reinforce the observation that trading consumes liquidity at least partly. Nevertheless, the empirical results do not refute the hypothesis that the intraday market is partly resilient. Concluding, hypothesis II b (The intraday market is resilient) cannot be rejected but hypothesis II a.

Hypothesis III a (The market depth is negatively correlated with intraday trading activity) cannot be falsified within the scope of the analyzed market data.

The overall model results of the linear regressions show adjusted $\mathrm{R}$ square values 0.5519 for the number of trades and 0.4522 for the trading volume. Those model fits support the hypotheses that intraday trading activity is determined by intraday deviations from the day-ahead planning (VIa and b). Furthermore French trading volumes, wind and solar power forecast errors and unplanned power plant outages significantly increase the number of trades and the trading volume. The unobserved determinants foreign demand and supply, CHP optimizations and intraday trading positions may account for a further share of the variance of trading volume and the number of trades yet are not considered in this analysis due to missing data.

As expected, trading activity is significantly increased by French trades, wind and solar power forecasts and outages which supports hypothesis VI a/b. However the regression coefficients on trading volume are different in size (table V). In a fundamental model perspective, a one MW increase of French trades cannot increase trading volume by 1.86 . The coefficients of the wind forecast error (0.51) and solar forecast errors (0.18) deviate significantly from the value of one which would be observed if the TSOs trade the deviations immediately as they appear. The coefficients smaller than one indicate that the TSOs internally match wind forecast errors, solar forecast errors and load forecast errors of opposite signs and only trade the net deviation in the intraday market. The same rationale applies to unplanned power plant outages. Of an outage of $1000 \mathrm{MWh}$, on average $131 \mathrm{MWh}$ were traded in the GIME. Power plant owners may compensate outages rather within their own portfolio (matching with other intraday long positions or ramping up of unused power plants, including highly flexible water pump storage plants) or via unobservable OTC trades. The different impacts of the independent variables on trading activity give support for the trading model (hypothesis VII b).

During the off-peak one and -two periods, on Sundays and on Mondays, the average BAS, high to low difference and price variance are significantly larger and the trading activity is significantly lower than during the reference groups peak and Wednesday. This stands in contrast to the assumptions of the fundamental model according to which the liquidity provision 
through power plant owners depends only on the available power plant capacities. After controlling for extreme merit-order shape effects the remaining liquidity indicators should be determined in the same way by the independent variables. The different price reactions during the peak and off-peak periods indicate that trading strategies have a market impact in the GIME. The missing office occupation of small market participants during the off-peak periods and on Sundays reduces the total number of market participants and thus seems to reduce competition. Trading strategies like the retention of capacity or offering available power plant capacities at non-competitive prices aim at the maximization of trading profits and may increase the average BAS, the high to low difference and price variance. These empirical observations indicate that the fundamental model of liquidity does not explain liquidity exhaustively.

The greater the squared difference between the hourly day-ahead equilibrium price and the two years day-ahead average of 47.81 Euro, the significantly higher are the high to low difference and the price variance. A reference value for the impact of merit-order extremes on the volatility indicators under the assumptions of the fundamental or the trading model is missing. Thus, hypotheses $\mathrm{V}$ a and $\mathrm{V} \mathrm{b}$ are both not falsified. ${ }^{23}$

\section{CONCLUSION AND OUTLOOK}

In this paper, a fundamental and a trading model of liquidity in the German intraday market for electricity are developed. In the fundamental model, only the patient power plant owners with available and flexible power plant capacities offer liquidity while risk-averse impatient traders with intraday imbalances trade against the power plant owners and consume the offered liquidity. According to the alternative trading model, the impatient traders are less risk averse and try to increase their revenues by behaving like patient traders. They do not trade immediately as a deviation from the day-ahead schedules appears and may trade via limit orders, thus increasing liquidity in addition to patient traders. Commonly used liquidity indicators are reviewed from literature. The relevance of the bid ask-spread, resiliency, market depth, price volatility, trading volume and the number of trades in the GIME are analyzed in this paper. Trading in the German intraday market occurs due to intraday deviations from the day-ahead planning that are unplanned power plant outages, the wind forecast error, the solar power forecast error, the load forecast error, foreign demand and supply, combined heat and

\footnotetext{
${ }^{23}$ The significantly positive influence of merit-order extremes on the number of trades may indicate that electricity traders prefer to trade with small quantities per trade and thus a higher number of trades during delivery hours with extreme prices. This behavior intends to prevent the market from becoming nervous.
} 
power plant optimizations and intraday trading positions. Further determinants of intraday liquidity are the merit-order shape, time of the day and day of the week effects.

To assess the explanatory power of either the fundamental or the trading model of liquidity, theoretical research hypotheses about the relationships between the indicators of liquidity and the intraday deviations from the day-ahead planning and the liquidity indicators and the meritorder are formulated. Summarizing the empirical results, the hypothesis that the fundamental model explains liquidity can be rejected but the proposition that the fundamental model does not explain intraday liquidity at all can also be rejected. Intraday deviations from the dayahead planning consume liquidity which is provided by power plant owners as indicated by the positive correlation of price variance with intraday trading activity. Furthermore the high to low difference and price variance are significantly higher, when the fundamental meritorder is steep as indicated by extreme day-ahead prices. The explanatory power of the trading model of liquidity is confirmed. An increasing number of actively trading market participants may decrease the size of the average BAS and increase intraday trading activity.The trading volume and the number of trades both do not decrease the average BAS in the GIME, when the number of active market participants is controlled for. The regression coefficients of the determinants of liquidity on the indicators of liquidity are different in size which indicates that impatient traders match contrary intraday positions within their portfolios before they close the remaining net deviations from the day-ahead planning in the intraday market. Thus, trading behaviour has a significant influence on liquidity in the GIME.

Missing data limits this study. Further research about other price based liquidity measures like the quoted and effective bid ask-spread or the hourly price-demand function may be undertaken as soon as order book data becomes available. Fundamental determinants like the hourly load forecast error, foreign demand and supply (apart from French demand and supply), intraday optimizations of combined heat and power plants and trading positions may play an important role in explaining intraday liquidity. Further research might also focus on the question in how far the number of active market participants is responsible for the often observed negative correlation between the BAS and trading volume. 


\section{Appendices}

TSO reserve power product demand Germany 2011

\begin{tabular}{|c|c|c|c|}
\hline $\begin{array}{l}\text { Reserve } \\
\text { power } \\
\text { product }\end{array}$ & & $\begin{array}{l}\text { Minimum } \\
\text { MW }\end{array}$ & $\begin{array}{l}\text { Maximum } \\
\text { MW }\end{array}$ \\
\hline \multirow{2}{*}{ Primary } & $\begin{array}{l}\text { Positive/ } \\
\text { negative }\end{array}$ & 612 & 624 \\
\hline \multirow{2}{*}{ Secondary } & Positive & 2073 & 2231 \\
\cline { 2 - 4 } & Negative & 2044 & 2163 \\
\hline \multirow{2}{*}{ Tertiary } & Positive & 1812 & 2600 \\
\cline { 2 - 4 } & Negative & 2118 & 2742 \\
\hline \multirow{2}{*}{ Total } & Positive & 4497 & 5455 \\
\cline { 2 - 4 } & Negative & 4774 & 5529 \\
\hline \multirow{2}{*}{ Average } & Positive & \multicolumn{2}{|c|}{4976} \\
\cline { 2 - 4 } & Negative & \multicolumn{2}{|c|}{5152} \\
\hline \multirow{2}{*}{ Source: $w W$} & .regelleistung.net \\
\hline
\end{tabular}

Source: www.regelleistung.net

Missing PV Data

\begin{tabular}{|l|l|}
\hline Grid area & Missing PV data \\
\hline $\mathbf{5 0}$ Hertz & $01.01 .2010-31.12 .2010$ \\
\hline Amprion & $01.01 .2010-30.06 .2010$ \\
\hline Tennet & $01.01 .2010-28.02 .2010$ \\
\hline TransnetBW & $01.01 .2010-31.12 .2010$ \\
\hline
\end{tabular}




\section{References}

Ahn, H.-J., Bae, K.-H., Chan, K., 2001. Limit Orders, Depth, and Volatility: Evidence from the Stock Exchange of Hong Kong. Journal of Finance, 56, 767-788.

Amihud, Y., 2002. Illiquidity and stock returns: cross-section and time-series effects. Journal of Financial Markets, 5, 31-56.

Amihud, Y., Mendelson, H., 1986. Asset Pricing and the Bid-Ask Spread. Journal of Financial Economics, 17, 223-249.

Amihud, Y., Mendelson, H., 1991. Liquidity, Asset Prices and Financial Policy. Financial Analysts Journal, 47, 56-66.

Arnott, R.D., Wagner, W.H., 1990. The Measurement and Control of Trading Costs. Financial Analysts Journal, 46, 73-80.

Bessembinder, H., Kaufman, H.M., 1997. A Comparison of Trade Execution Costs for NYSE and NASDAQ-Listed Stocks. The Journal of Financial and Qunatitative Analysis, 32, 287-310.

BNA, 2012. Eckpunktepapier zur Weiterentwicklung des Ausgleichsenergiepreises, 1-7.

Bodurtha, S.G., Quinn, T.E., 1990. Does Patient Program Trading Really Pay? Financial Analysts Journal, 46, 35-42.

Borggrefe, F., Neuhoff, K., 2011. Balancing and Intraday Market Design: Options for Wind Integration. DIW Discussion Papers. Berlin.

Bueno-Lorenzo, M., Moreno, M.Á., Usaola, J., 2013. Analysis of the Imbalance Price Scheme in the Spanish Electricity Market: A wind power test case. Energy Policy, 62, 1010-1019.

Bundesverband Solarwirtschaft e. V., 2012. Statistische Zahlen der deutschen Solarstrombranche (Photovoltaik).

Copeland, T.E., Galai, D., 1983. Information Effects on the Bid-Ask Spread. The Journal of Finance, 38, 1457-1469.

Corwin, S.A., Schultz, P., 2012. A Simple Way to Estimate Bid-Ask Spreads from Daily High and Low Prices. The Journal of Finance, 67, 719-760.

DENA, 2010. Integration of Renewable Energy Sources into the German Power Supply System in the 2015-2020 period with Outlook to 2025. Final report.

Ellersdorfer, I., Hundt, M., Sun, N., Voß, A., 2008. Preisbildungsanalyse des deutschen Elektrizitätsmarktes. Universität Stuttgart.

Engle, R., Fleming, M., Ghysels, E., Nguyen, G., 2011. Liquidity and Volatility: Evidence from a New Class of Dynamic Order Book Models. Working Paper. 
ENTSOE, 2011. NTC map for the winter season 2010-2011. Retrievable under https://www.entsoe.eu/index.php?id=391.

ETSO, 2007. Current State of Intraday Markets in Europe. ETSO Report.

Flinkerbusch, K., Heuterkes, M., 2010. Cost reduction potentials in the German market for balancing power. Energy Policy, 38, 4712-4718.

Foucault, T., Kadan, O., Kandel, E., 2005. Limit Order Book as a Market for Liquidity. Review of Financial Studies, 18, 1171-1217.

Frestad, D., 2012. Liquidity and dirty hedging in the Nordic electricity market. Energy Economics, 34, 1341-1355.

Furió, D., Lucia J. J., Meneu V., 2009. The Spanish Electricity Intraday Market: Prices and Liquidity Risk. Working Paper.

Goyenko, R.Y., Holden, C.W., Trzcinka, C.A., 2009. Do liquidity measures measure liquidity? Journal of Financial Economics, 92, 153-181.

Handa, P., Schwartz, R.A., 1996. Limit Order Trading. The Journal of Finance, 51, 18351861.

Haubrich, H.-J., 2008. Gutachten zur Höhe des Regelenergiebedarfs. Gutachten im Auftrag der Bundesnetzagentur für Elektrizität, Gas, Telekommunikation, Post und Eisen-bahnen. Bonn.

Hirschhausen, C. v., Weigt, H., Zachmann, G., 2007. Preisbildung und Marktmacht auf den Elektrizitätsmärkten in Deutschland. Grundlegende Mechanismen und empirische Evidenz. Verband der Industriellen Energie- und Kraftwirtschaft e.V., 1-71.

Jiang, G., Wang, S., Dong, H., 2011. A Survey of Limit Order Book Modeling in Continuous Auction Market. Intelligent Systems and Applications (ISA), 1-4.

Jorgensen, C., Ropenus, S., 2008. Production price of hydrogen from grid connected electrolysis in a power market with high wind penetration. International Journal of Hydrogen Energy, 33, 5335-5344.

Kempf, A., Mayston, D., Yadav P. K., 2009. Resiliency in Limit Order Book Markets: A Dynamic View of Liquidity. AFA 2009 San Francisco Meetings Paper.

Korajczyk, R.A., Sadka, R., 2008. Pricing the commonality across alternative measures of liquidity. Journal of Financial Economics, 87, 45-72.

Kyle, A.S., 1985. Continuous Auctions and Insider Trading. Econometrica, 53, 1315-1335.

Lee, C.M. C., Ready, M.J., 1991. Inferring Trade Direction from Intraday Data. The Journal of Finance, 46, 733-746. 
Lehmann, P., Creutzig, F., Ehlers, M.-H., Friedrichsen, N., Heuson, C., Hirth, L., Pietzcker, R., 2012. Carbon Lock-Out: Advancing Renewable Energy Policy in Europe. Energies, 5, 323-354.

Liu, W., 2006. A liquidity-augmented capital asset pricing model. Journal of Financial Economics, 82, 631-671.

Marshall, B.R., Nguyen, N.H., Visaltanachoti, N., 2012. Commodity Liquidity Measurement and Transaction Costs. Review of Financial Studies, 25, 599-638.

Möller, C., Rachev, S.T., Fabozzi, F.J., 2011. Balancing energy strategies in electricity portfolio management. Energy Economics, 33, 2-11.

Nicolosi, M., 2010. Wind power integration and power system flexibility-An empirical analysis of extreme events in Germany under the new negative price regime. Energy Policy, 38, $7257-7268$.

Petersen, M.A., 2008. Estimating Standard Errors in Finance Panel Data Sets: Comparing Approaches. Review of Financial Studies, 22, 435-480.

RTE, 2012. Bilans du Mécanisme d'Ajustement. Retrievable under http://www.rtefrance.com/fr/mediatheque/documents/l-electricite-en-france-donnees-et-analyses-16fr/publications-mensuelles-17-fr/bilans-du-mecanisme-d-ajustement-19-fr.

Sarr, A., Lybek T., 2002. Measuring Liquidity in Financial Markets. IMF Working Paper.

Scharff, R., Amelin M., 2011. A Study of Electricity Market Design for Systems with High Wind Power Penetration. 8th International Conference on the European Electricity System.

Sensfuß, F., Ragwitz, M., Genoese, M., 2008. The merit-order effect: A detailed analysis of the price effect of renewable electricity generation on spot market prices in Germany. Energy Policy, 36, 3086-3094.

UBA, 2013. Kraftwerke in Deutschland. (Downloadable at: http://www.umweltbundesamt.de/sites/default/files/medien/378/dokumente/kraftwerke_de ab_100_mw.xls ).

Ullrich, A., 2009. EEX Market Monitor. Quarterly Report by the Market Surveillance.

Ummels, B.C., Gibescu, M., Pelgrum, E., Kling, W.L., Brand, A.J., 2007. Impacts of Wind Power on Thermal Generation Unit Commitment and Dispatch. IEEE Transactions on Energy Conversion, 22, 44-51.

Weber, C., 2010. Adequate intraday market design to enable the integration of wind energy into the European power systems. Energy Policy, 38, 3155-3163.

Windmonitor, 2012. Retrievable under http://windmonitor.iwes.fraunhofer.de/windwebdad/www_reisi_page_new.show_page?pa ge_nr=363\&lang=de 
Wooldridge, J., 2011. Introductory econometrics. A modern approach. South-Western.

Zachmann, G., 2008. Electricity wholesale market prices in Europe: Convergence? Energy Economics, 30, 1659-1671. 